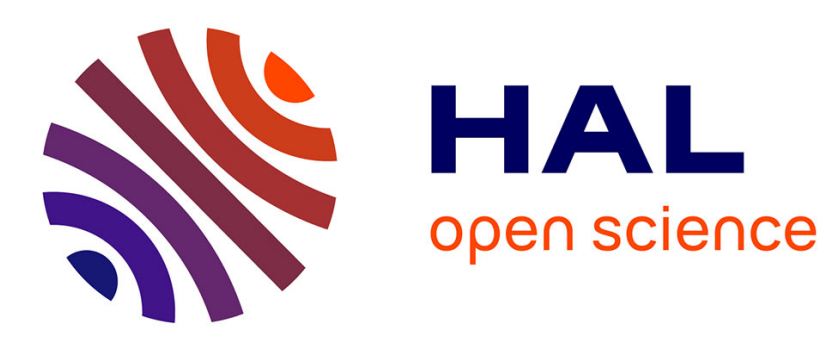

\title{
Carbon nanotubes: Culprit or witness of air pollution?
} Jelena Kolosnjaj-Tabi, Henri Szwarc, Fathi Moussa

\section{To cite this version:}

Jelena Kolosnjaj-Tabi, Henri Szwarc, Fathi Moussa. Carbon nanotubes: Culprit or witness of air pollution?. Nano Today, 2017, 15, pp.11-14. 10.1016/j.nantod.2017.04.010 . hal-02893422

\section{HAL Id: hal-02893422 https: / hal.sorbonne-universite.fr/hal-02893422}

Submitted on 8 Jul 2020

HAL is a multi-disciplinary open access archive for the deposit and dissemination of scientific research documents, whether they are published or not. The documents may come from teaching and research institutions in France or abroad, or from public or private research centers.
L'archive ouverte pluridisciplinaire HAL, est destinée au dépôt et à la diffusion de documents scientifiques de niveau recherche, publiés ou non, émanant des établissements d'enseignement et de recherche français ou étrangers, des laboratoires publics ou privés. 


\section{Carbon nanotubes: culprit or witness of air pollution?}

Jelena Kolosnjaj-Tabi ${ }^{\dagger^{*}}$, Henri Szwarc ${ }^{\dagger}$, Fathi Moussa ${ }^{\dagger t^{*}}$

${ }^{\dagger}$ LETIAM, Lip(Sys)², IUT d’Orsay, Paris-Saclay University, Plateau de Moulon, 91400 Orsay, France.

$¥$ Department of Biochemistry, Trousseau-La Roche Guyon Hospital group, Assistance Publique - Hôpitaux de Paris, Pierre et Marie Curie-Paris 6 University, Paris, France

*Corresponding authors: Jelena Kolosnjaj-Tabi (kolosnjaj@gmail.com), Fathi Moussa (fathi.moussa@u-psud.fr)

\section{Summary:}

The notorious $\mathrm{PM}_{2.5}(2.5 \mu \mathrm{m}$ diameter particulate matters $)$ that can reach human lungs, considered as responsible for most deleterious effects of air pollution, are now unmasked. Anthropogenic carbon nanotubes and other carbon nanoparticles were unambiguously identified as the major components of $\mathrm{PM}_{2.5}$ in alveolar macrophages of Parisian children. Obviously, carbon nanoparticles cannot be distinguished from lamellar bodies by optical microscopy only. Thus, previous studies based on optical microscopy, linking carbon content of alveolar macrophages to lung dysfunction, must be reconsidered. The remaining challenge is to determine whether carbon nanoparticles are the culprit or are only markers of pollution exposure.

Keywords: Carbon nanotubes, Particulate matter, Air pollution, Lungs, Lamellar bodies

\section{Highlights:}


- Particulate matter (PM) was exhaustively characterized in asthmatic children's lungs

- Anthropogenic carbon nanotubes were rare but present in all samples

- Optical microscopy (OM) cannot discriminate between PM and lamellar bodies

- Studies where carbon content was assessed only by OM should be reconsidered

\section{Common and widespread}

Have you ever wondered what do convenient Indian auto-rickshaws, powerful American heavy-duty engines and popular European (not necessarily German) cars have in common? They have all been reported to generate carbon nanotubes (CNTs) and emit it within their exhausts [1-3]. Carbon nanotubes, if an introduction is required, are cylindrical, $\mathrm{sp}^{2}$-bonded carbon nanostructures that can be single- or multi- walled. They can be either synthesized in a laboratory under controlled conditions, where rare structural defects and low impurity content result in their unique and exceptional physical properties, or made (less perfectly and less purely) outside the labs in different processes of common biomass combustion [4].

\section{Diesel, the sustained source}

Biomass burning-derived particles contribute to the major share of airborne carbonaceous particles. Among them, traffic-derived, especially diesel-derived particulates (Figure 1A), have been recognized as major particulate matter (PM) components [5]. Interestingly, in the opinion of the International Agency for Research on Cancer, based on the evidence of increased risk for lung cancer, diesel engine exhaust is carcinogenic to humans (Group 1). Be that as it may, according to the statistics published by the European Automobile Manufacturers association (http://www.acea.be/statistics/tag/category/share-of-diesel-in-newpassenger-cars), the proportion of diesel in new passenger cars continues increasing and 
currently represents more than $50 \%$ of sold vehicles. The ambulant sources of diesel-derived particulates, including airborne anthropogenic carbon nanotubes [6], consequently, continue growing.

\section{Commonality between ice core, ancient steel, and ... children}

Carbon nanotubes appear as past [7] and present invaders of the atmosphere, and what is alarming is that they can reach our lungs. Unfortunately, that is what we recently confirmed [8]. Inhaled CNTs (similar to those collected in airborne dusts and vehicle exhausts) were present in all examined samples $(\mathrm{N}=69)$ obtained from Parisian asthmatic children [8].

\section{Deceptive appearance}

The idea that black carbon [5] penetrates the lungs is not new and was already proposed in a study performed on children from Leicestershire [9]. This study reported a strong dosedependent link between the carbon content in alveolar macrophages and the decline in lung function [9]. But carbon, characterized only by optical microscopy [9], was probably mistaken with black-appearing lamellar bodies (Figure 1B), the lipid storage and secretory organelles, present within alveolar cells [8]. Obviously, carbon nanoparticles cannot be distinguished from lamellar bodies by optical microscopy only [8]. Thus, previous studies based on optical microscopy, linking carbon content of alveolar macrophages to lung dysfunction [9], must be reconsidered .

Another study reported that CNTs were extracted from the lungs of the victims of the World Trade Center attack [10], but the samples were only observed by means of low magnification transmission electron microscopy (TEM) [10], which might provide erroneous evidence, as 
pulmonary surfactant filaments (Figure C) [8] might strongly resemble filamentous singlewalled CNT bundles (Figure D).

\section{A needle in a haystack}

While the synthesis of novel nanomaterials blooms and blossoms, the identification studies of airborne nanoparticles are still rather scarce. Moreover, qualitative identification studies of inhaled PM are extremely rare and only approximate, which is mainly due to the complexity of finding carbon particulates within carbon-based biological samples.

Particulate matter, including CNTs, can be characterized only by a limited number of techniques, which are not common in clinics. And yet, clinically applied research definitely longs for appropriate easy-to-use methods of detection of airborne carbon nanoparticles.

In our recent study [8], we used optical microscopy and TEM to prescreen biological samples (lung cells and broncho-alveolar lavage fluids, respectively), and used specific techniques, such as energy dispersive X-ray spectroscopy, high-resolution TEM, near infra red fluorescence microscopy and Raman spectroscopy. These methods allowed us to characterize the PM present in biological samples and discriminate between lamellar bodies, lung surfactant and PM. Consistent with theoretical calculations, which suggested the rareness of inhaled PM even after important particulate exposure (concretely: a daily deposition of about $50 \mu \mathrm{g}$ of PM would result in particles covering of 0.2 to 0.5 millionths of the lung surface area) [11], our results showed that inhaled PM were particularly rare [8]. In addition, intracellular PM mainly consisted of anthropogenic CNTs and some amorphous black carbon nanoparticles (Figure E), which cannot be identified by optical microscopy, contrarily to what was reported earlier [8]. 


\section{Causal or non-causal bases}

Particulate-matter-associated pathological conditions, including respiratory and cardiovascular disease, cancer and diabetes, to mention but a few, have been extensively reported. In contrast, quantitative assessments of the threshold of the PM that penetrates our bodies and is responsible for deleterious health effects are inexistent. Is that so because there are no causal effects [12] between airborne PM levels and health effects or because health effects are a result of multiple (particle-related and particle non-related) variables? While epidemic studies blamed the PM derived from open fire biomass burning, a very recent study involving more than 10000 Malawian children fund no evidence that cleaner burning biomass-fuelled cook stoves reduced the risk of pneumonia in young children [13]. Air pollution derived from biomass burning in open fires had previously been associated with premature mortality, but this study suggests that cook stoves combustion is not the only responsible factor [13]. While rubbish burning and tobacco smoke might have added to PM pollutants that impacted Malawian children's health [13], societal and psychological factors might be implicated and play the role of non-toxicological variables in PM-health associations [12] in First World countries.

\section{So help me Nanotechnologist}

Besides being a general societal issue, particulate pollutants should attract more nanotechnologists attention. In a first approach, the purpose of our study was to characterize the particulates that penetrate the lungs and the lungs of Parisian children were found to contain CNTs [8]. Further studies are evidently necessary to establish any potential link between CNT-lung content and lung dysfunction. Additional research is necessary to 
determine which ones among diesels engine exhausts constituents are the most responsible for deleterious health outcomes. A method of detection and quantification of intracellular PM (and especially CNTs) should be found, and should, preferentially, be applicable in clinics. If ascertained for health nuisance, appropriate measures should be taken (e.g. filters and air purifiers should be developed and applied) to diminish atmospheric CNT burden. Besides, there might obviously be other (toxicological) components, including volatile ones, involved in pollution's potential deleterious effects [14], and their effect should also be assessed.

\section{Fine-tuning the research}

Observational epidemiological studies reporting relationships between PM exposure and morbidity/mortality are prone to confusions and interpretational uncertainties [5]. While the “carbon content" [9] or "CNT content" [10] are probably yet another example of dubious identifications of carbonaceous nanoparticles [5] in biological samples, the anthropogenic CNTs might represent a potential risk, and their implication should be assessed in detail. Indeed this should add to different laboratory studies that found more or less diverging outcomes after CNTs administration [15-22]. In addition, as it has been suggested that alveolar removal might occur [11], and demonstrated that CNTs might degrade [23, 24], empirical evidence of PM accumulation over a lifetime exposure should be investigated.

In whatever way, even if CNTs are slightly harmful or non-toxic, due to their large specificsurface and ability to adsorb a large variety of substances, they can probably act as nanovectors for some hazardous pollutants present in the particulate mix. Forthcoming studies should thus help answering the question, are CNTs the culprit or just a witness of the exposure to air pollution? 
Finally, if CNTs are guilty as charged, handy and reliable methods for their specific detection in biological samples should be developed. In the same time, further effort in the development and application of exhaust filters and air purifiers should be supported by authorities.

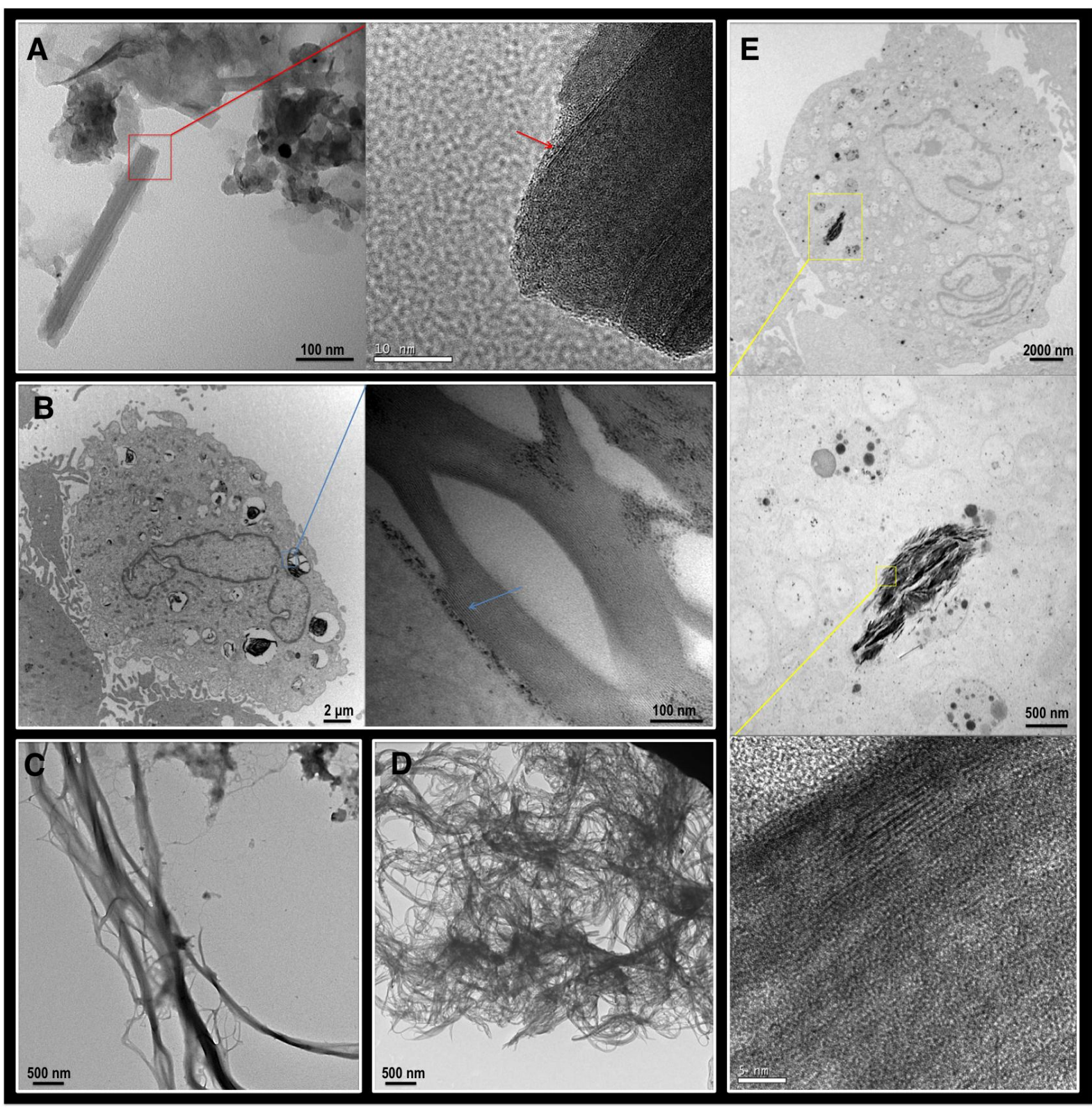

Figure: Ultrastructural characteristics of airborne carbon nanotubes and surfactants: A) Left: diesel exhaust TEM micrograph showing spherical and CNT-like carbon nanoparticles and right: the HR-TEM micrograph of the red-squared zone confirming the structure of a multi-walled anthropogenic CNT, exhibiting a characteristic interlayer spacing of approximately $0.33 \mathrm{~nm}$ (red arrow); B) Left: A cell obtained from an asthmatic child, 
showing several black-appearing lamellar bodies, one of which (blue square) is magnified on the right: lamellar-body surfactant with its characteristic, graphite-like fringes (blue arrow); C) Filament-like structures obtained from broncho-alveolar fluid lysates, which become decreasingly electron-dense with the increasing electron microscope magnification (not shown on figure); D) Purified single-walled carbon nanotubes bundles, which remain electron-dense with the increasing electron microscope magnification (not shown on figure);

E) From top to bottom: An alveolar cell containing CNT-like structures (yellow square), followed by its magnified TEM and HR-TEM micrograph, confirming the presence of graphitic layers characteristic for multi-walled CNTs.

\section{References:}

1. Lagally C, Reynolds C, Grieshop A, Kandlikar M, Rogak S. Carbon nanotube and fullerene emissions from spark-ignited engines. Aerosol Science and Technology. 2012;46(2):156-64.

2. Jung HS, Miller A, Park K, Kittelson DB. Carbon nanotubes among diesel exhaust particles: real samples or contaminants? Journal of the Air \& Waste Management Association. 2013;63(10):1199-204.

3. Evelyn A, Mannick S, Sermon P. Unusual carbon-based nanofibers and chains among diesel-emitted particles. Nano Letters. 2003;3(1):63-4.

4. Murr LE, Bang J, Esquivel E, Guerrero P, Lopez D. Carbon nanotubes, nanocrystal forms, and complex nanoparticle aggregates in common fuel-gas combustion sources and the ambient air. Journal of Nanoparticle Research. 2004;6(2):241-51.

5. Long CM, Nascarella MA, Valberg PA. Carbon black vs. black carbon and other airborne materials containing elemental carbon: Physical and chemical distinctions. Environmental Pollution. 2013;181:271-86.

6. Swanson JJ, Febo R, Boies AM, Kittelson DB. Fuel Sulfur and Iron Additives Contribute to the Formation of Carbon Nanotube-like Structures in an Internal Combustion Engine. Environmental Science \& Technology Letters. 2016;3(10):364-8.

7. Murr L, Esquivel E, Bang J, De La Rosa G, Gardea-Torresdey J. Chemistry and nanoparticulate compositions of a 10,000 year-old ice core melt water. Water research. 2004;38(19):4282-96.

8. Kolosnjaj-Tabi J, Just J, Hartman KB, Laoudi Y, Boudjemaa S, Alloyeau D, et al. Anthropogenic carbon nanotubes found in the airways of Parisian children. EBioMedicine. 2015;2(11):1697-704.

9. Kulkarni N, Pierse N, Rushton L, Grigg J. Carbon in airway macrophages and lung function in children. New England Journal of Medicine. 2006;355(1):21-30. 
10. Wu M, Gordon RE, Herbert R, Padilla M, Moline J, Mendelson D, et al. Case report: Lung disease in World Trade Center responders exposed to dust and smoke: carbon nanotubes found in the lungs of World Trade Center patients and dust samples. Environmental health perspectives (Online). 2010;118(4):499.

11. Watson AY, Valberg PA. Alternative hypotheses linking outdoor particulate matter with daily morbidity and mortality. Inhalation toxicology. 1998;10(7):641-62.

12. Valberg PA. Possible Noncausal Bases for Correlations Between Low Concentrations of Ambient Particulate Matter and Daily Mortality. Nonlinearity in biology, toxicology, medicine. 2003;1(4):15401420390271137.

13. Mortimer K, Ndamala CB, Naunje AW, Malava J, Katundu C, Weston W, et al. A cleaner burning biomass-fuelled cookstove intervention to prevent pneumonia in children under 5 years old in rural Malawi (the Cooking and Pneumonia Study): a cluster randomised controlled trial. The Lancet. 2017;389(10065):167-75.

14. Kelly FJ, Fussell JC. Size, source and chemical composition as determinants of toxicity attributable to ambient particulate matter. Atmospheric Environment. 2012;60:50426.

15. Lam CW, James JT, McCluskey R, Hunter RL. Pulmonary toxicity of single-wall carbon nanotubes in mice 7 and 90 days after intratracheal instillation. Toxicological Sciences. 2004;77(1):126.

16. Warheit DB, Laurence B, Reed KL, Roach D, Reynolds G, Webb T. Comparative pulmonary toxicity assessment of single-wall carbon nanotubes in rats. Toxicological Sciences. 2004;77(1):117.

17. Shvedova AA, Kisin ER, Mercer R, Murray AR, Johnson VJ, Potapovich AI, et al. Unusual inflammatory and fibrogenic pulmonary responses to single-walled carbon nanotubes in mice. American Journal of Physiology-Lung Cellular and Molecular Physiology. 2005;289(5):L698.

18. Poland CA, Duffin R, Kinloch I, Maynard A, Wallace WAH, Seaton A, et al. Carbon nanotubes introduced into the abdominal cavity of mice show asbestos-like pathogenicity in a pilot study. Nature Nanotechnology. 2008;3(7):423-8.

19. Takagi A, Hirose A, Nishimura T, Fukumori N, Ogata A, Ohashi N, et al. Induction of mesothelioma in p53+/- mouse by intraperitoneal application of multi-wall carbon nanotube. Journal of Toxicological Sciences. 2008;33(1):105-16.

20. Muller J, Delos M, Panin N, Rabolli V, Huaux F, Lison D. Absence of Carcinogenic Response to Multiwall Carbon Nanotubes in a 2-Year Bioassay in the Peritoneal Cavity of the Rat. Toxicological Sciences. 2009;110(2):442-8.

21. Mutlu GM, Budinger GRS, Green AA, Urich D, Soberanes S, Chiarella SE, et al. Biocompatible nanoscale dispersion of single-walled carbon nanotubes minimizes in vivo pulmonary toxicity. Nano letters. 2010;10(5):1664-70.

22. Kolosnjaj-Tabi J, Hartman KB, Boudjemaa S, Ananta JS, Morgant G, Szwarc H, et al. In Vivo Behavior of Large Doses of Ultrashort and Full-Length Single-Walled Carbon Nanotubes after Oral and Intraperitoneal Administration to Swiss Mice. Acs Nano. 2010;4(3):1481-92.

23. Kotchey GP, Zhao Y, Kagan VE, Star A. Peroxidase-mediated biodegradation of carbon nanotubes in vitro and in vivo. Advanced drug delivery reviews. 2013;65(15):1921-32. 24. Elgrabli D, Dachraoui W, Ménard-Moyon C, Liu XJ, Bégin D, Bégin-Colin S, et al. Carbon Nanotube Degradation in Macrophages: Live Nanoscale Monitoring and Understanding of Biological Pathway. Acs Nano. 2015;9(10):10113-24. 